\title{
Prolonged treatment planning can increase real rectal dose in 3D brachytherapy for cervical cancer
}

\author{
Zuzana Vlachová, MD',2, Martin Dolezel, PhD!,2, Katerina Svozilova, MSc', Paulina Jaskova, MSc', Denisa Vitaskova, PhD!, \\ Marcel Matzenaver, PhD ${ }^{4}$, Jan Stuk, MD5 , Igor Hartmann, PhD² \\ 'Department of Oncology, Palacký University Medical School \& Teaching Hospital, Olomouc, Czech Republic, ${ }^{2}$ Faculty of Medicine, Palacký \\ University Olomouc, Olomouc, Czech Republic, ${ }^{3}$ First Faculty of Medicine, Charles University, Prague, Czech Republic, ${ }^{4}$ Comprehensive Cancer \\ Centre, Novy Jicin, Czech Republic, ${ }^{5}$ Comprehensive Cancer Centre Multiscan, Pardubice, Czech Republic
}

\begin{abstract}
Purpose: The purpose of this study was to evaluate the influence of 3D brachytherapy planning time on the real dose distribution.

Material and methods: 10 patients with cervical cancer were evaluated using 2 computed tomography (CT) scans brachytherapy. The first scan was performed after the insertion of UVAG applicators, and the second was done after creating the treatment plan, just before the irradiation of first and third fraction. Both plans were compared in terms of changes of volumes and differences in the dose for high-risk organs using GEC-ESTRO Working Group parameters.

Results: The median planning time was 54 minutes (36-64 minutes). The absolute median change of volume for bladder, rectum, and sigmoid was $32.1 \mathrm{~cm}^{3}\left(1.6-108.6 \mathrm{~cm}^{3}\right), 5.6 \mathrm{~cm}^{3}\left(0.4-61.8 \mathrm{~cm}^{3}\right)$, and $8.4 \mathrm{~cm}^{3}\left(0.2-74.1 \mathrm{~cm}^{3}\right)$, respectively. This difference led to an increased dose for bladder and sigmoid for $D_{0.1 c c}$ by $46.7 c G y$ and $25.7 \mathrm{cGy}$, for $\mathrm{D}_{1 \mathrm{cc}}$ by $59.2 \mathrm{cGy}$ and $11.8 \mathrm{cGy}$, and for $\mathrm{D}_{2 \mathrm{cc}}$ by $44.7 \mathrm{cGy}$ and $10 \mathrm{cGy}$, respectively, per each fraction. Measured volume change in case of rectum led to a decreased dose per each fraction for $\mathrm{D}_{0.1 \mathrm{cc}}$ with $7.1 \mathrm{cGy}$, for $\mathrm{D}_{1 \mathrm{cc}}$ with $3.5 \mathrm{cGy}$, and for $\mathrm{D}_{2 \mathrm{cc}}$ with $4.8 \mathrm{cGy}$. We observed that statistically significant dependency between the planning time and the dose was proved for rectum. The longer time for planning, the higher dose for rectum. The correlation coefficient for $\mathrm{D}_{0.1 \mathrm{cc}}$ was 0.6715 $(p=0.0061)$, for $\mathrm{D}_{1 \mathrm{cc}}$ was $0.6404(p=0.011)$, and for $\mathrm{D}_{2 \mathrm{cc}}$ was $0.5891(p=0.0197)$.

Conclusions: Extended treatment planning time for brachytherapy due to the changes in topography of small pelvis can lead to different dose in high-risk organs than previously planned. It seems that the most significant changes are related to rectum.

J Contemp Brachytherapy 2020; 12, 2: 118-123 DOI: https://doi.org/10.5114/jcb.2020.94580
\end{abstract}

Key words: cervical cancer, 3D brachytherapy, treatment planning.

\section{Purpose}

Cervical cancer is the most common gynecological malignancy, representing the fourth most common malignancy among women. Radiotherapy has been used for more than a century, with the first documented application of radium (Ra) performed in 1903, and the first cured patient reported in 1913. Radiation therapy is currently a method of choice in patients with early stage disease (I-IIA) and represents, in combination with chemotherapy, a standard treatment option for patients with locally advanced tumors.

Brachytherapy is an integral component of cervical cancer radiotherapy, significantly improving overall survival [1]. With technological progress and development of computed tomography/magnetic resonance (CT/MR) compatible applicators, 3D imaging was gradually implemented to brachytherapy treatment planning. The use of
CT and MR images allow to determine the exact target volume and contours of organs at risk (bladder, rectum, and sigmoid), followed with targeted plan optimization using $3 \mathrm{D}$ images $[2,3,4,5,6,7,8,9,10]$. Shin reported the effect of imaging methods on final plan quality, aiming at conformity of targeted volume and contouring of organs at risk [7]. The positive effect of 3D brachytherapy using magnetic resonance on locoregional recurrence and overall survival was recently published by Pötter [3,11].

Gynecological GEC-ESTRO working group published the $3 \mathrm{D}$ brachytherapy recommendations related to determination of targeted volumes, planning concept based on the dose volume histogram parameters (DVH), reconstruction of applicators, and basic principles and parameters for MR imaging [12,13,14,15]. With these guidelines, the Gynecological GEC-ESTRO working group presented a common concept and terminology for different clini- 
cal approaches and sources used in radiation. Magnetic resonance allows the delineation of the area with macroscopic tumor (gross tumor volume - GTV). The working group also recommends different clinical target volumes for areas with high-risk and intermediate-risk of recurrence (high-risk clinical target volume - HRCTV, intermediate-risk clinical target volume - IRCTV), and recommends also reporting the minimum applied dose in $90 \%$ and $100 \%\left(D_{90}, D_{100}\right)$ in the case of clinical target volume and minimum dosage applied for $0.1 \mathrm{~cm}^{3}, 1 \mathrm{~cm}^{3}$, and $2 \mathrm{~cm}^{3}\left(\mathrm{D}_{0.1 \mathrm{cc}}, \mathrm{D}_{1 \mathrm{cc},}\right.$ and $\left.\mathrm{D}_{2 \mathrm{cc}}\right)$ for organs at risk.

The undeniable clinical benefit is associated with more time-demanding process of contouring and planning, which leads to extended interval between imaging (after insertion of applicators) and radiation itself.

The purpose of this study was to evaluate the outcome and clinical influence of the planning time factor on resulting distribution dose.

\section{Material and methods}

Dynamic changes of topography of the small pelvis during brachytherapy planning in 10 patients who underwent chemoradiotherapy for locally advanced cervical cancer (cT2b cN0-1) were evaluated.

Patients underwent pelvic external irradiation with intensity modulated therapy (IMRT) 45 Gy per 1.8 Gy in 25 fractions, with concurrent weekly administration of cisplatin $\left(40 \mathrm{mg} / \mathrm{m}^{2}\right)$. The treatment was subsequently continued with 3D-based brachytherapy with prescribed dose of $4 \times 7 \mathrm{~Gy}$ for minimal coverage of $90 \%$ high-risk clinical target volume $\left(\mathrm{D}_{90} \mathrm{HRCTV}\right)$, twice a week using Utrecht CT/MR compatible applicator (Nucletron; Elekta, Stockholm, Sweden). During the procedure, the bladder was routinely emptied and instilled with $50 \mathrm{ml}$ of saline to maintain the anatomical geometry. All women were asked to follow dietary protocol to ensure empty rectum. Immediately after applicators insertion in operating room, patients were transported to brachytherapy room, where the $\mathrm{CT}$ acquisition was performed by $3 \mathrm{~mm}$ slice thickness using GE Healthcare LightSpeed [16]. Complete CT image datasets for brachytherapy were transferred to Oncentra treatment planning system version 4.3 (Elekta; Nucletron, Stockholm, Sweden) for contouring and planning. All patients were contoured by a single physician (Z.V.) and planned by a single physicist (K.S.).

The planning CT scan was used for creating a regular 3D plan using the Gynecological GEC-ESTRO working group recommendations. Aside from recommended dosage of $4 \times 7$ Gy for $D_{90}$ HRCTV, the DVH constrains for rectum, bladder, and sigmoid were also used. The limit summary equivalent dose in 2 Gy fraction for $2 \mathrm{cc}\left(\mathrm{EQD}_{2}\right.$ $\mathrm{D}_{2 \mathrm{cc}}$ ) for bladder was $90 \mathrm{~Gy}$, and for sigmoid and rectum 75 Gy. High-dose-rate brachytherapy was performed using ${ }^{192}$ Ir remote afterloading system (MicroSelectron, Elekta, Stockholm, Sweden), with the patients still lying on the CT table to minimize motion of applicators.

A second CT scan (confirmation CT) was performed in the first and third fraction of brachytherapy, after creating the plan just before the irradiation. After irradiation, the applicators were removed.
In a confirmatory $\mathrm{CT}$ scan, the clinical target volumes and high-risk organs were contoured. Applicators were reconstructed and this plan consisted of stepping source positions based on the original plan. Twenty plans based on planning CT scans and 20 confirmation plans based on confirmatory CT scans were compared in terms of changes of volumes and differences in doses to high-risk organs. At the same time, the relation between planning time and dose to organs at risk were evaluated. Plans created in less than 54 minutes versus plans generated in 54 minutes or more were compared. To evaluate the doses for bladder, sigmoid, and rectum, the Gynecological (GYN) GECESTRO working group doses parameters for $0.1 \mathrm{~cm}^{3}$, $1 \mathrm{~cm}^{3}$, and $2 \mathrm{~cm}^{3}\left(D_{0.1 \mathrm{cc}}, D_{1 \mathrm{cc},}\right.$ and $\left.\mathrm{D}_{2 \mathrm{cc}}\right)$ were used. The difference of dose between confirmation $\mathrm{CT}$ and planning CT for each dose parameter was assessed $(\Delta D)$, and the correlation coefficient was used to evaluate this association. Additionally, the correlation coefficient was used to express a linear relationship between two random variables $X, Y$. The sample correlation coefficient $R_{X, Y}$ of random variables $\mathrm{X}, \mathrm{Y}$ is a number defined by the relation:

$R_{X, Y}=\frac{S_{X, Y}}{\sqrt{S_{X}^{2} S_{Y}^{2}}}=\frac{S_{X, Y}}{S_{X} S_{Y}}$

where $\bar{X}=\frac{1}{n} \sum_{i=1}^{n} X_{i}$ is the average,

$S_{X}^{2}=\frac{1}{n-1} \sum_{i=1}^{n}\left(X_{i}-\bar{X}\right)^{2}$ is the sample variance, and

$S_{X, Y}=\frac{1}{n-1} \sum_{i=1}^{n}\left(X_{i}-\bar{X}\right)\left(Y_{i}-\bar{Y}\right)$ is the sample covariance.

$P$-value less than 0.05 was considered significant.

\section{Results}

The median planning time performing planning CT scan and confirmatory CT scan before the irradiation was 54 minutes (range, 36-64 minutes). In 10 patients, planning time was less than 54 minutes and in 10 patients was 54 minutes or more.

The median volume of the bladder in the planning CT scan was $119.6 \mathrm{~cm}^{3}$ and $141.0 \mathrm{~cm}^{3}$ in the confirmatory CT. The absolute median change of volume was $32.1 \mathrm{~cm}^{3}$ (range, $1.6-108.6 \mathrm{~cm}^{3}$ ). This change represents a difference of $27.9 \%$ from the original volume (range, $0.96-155.5 \%)$. This difference led to an increased median dosefordelta $\mathrm{D}_{0.1 \mathrm{cc}}$ by $46.7 \mathrm{cGy}$, fordeltaD $\mathrm{D}_{1 \mathrm{cc}}$ by $59.2 \mathrm{cGy}$, and for delta $\mathrm{D}_{2 \mathrm{cc}}$ by $44.7 \mathrm{cGy}$ per each single fraction (Table 1 , Figure $1 \mathrm{~A}-\mathrm{C}$ ).

The median volume of rectum in the planning CT scan was $45.5 \mathrm{~cm}^{3}$ and $41.6 \mathrm{~cm}^{3}$ in the confirmatory CT. The absolute median change was $5.6 \mathrm{~cm}^{3}$ (range, $0.4-61.8 \mathrm{~cm}^{3}$ ), with a difference of $14.4 \%$ from the original volume. This volume change led to decreased dose per each fraction for $D_{0.1 \mathrm{cc}}$ of $7.1 \mathrm{cGy}$, for $\mathrm{D}_{1 \mathrm{cc}}$ of $3.5 \mathrm{cGy}$, and for $\mathrm{D}_{2 \mathrm{cc}}$ of 4.8 cGy (Table 1, Figure 2A-C). 
Table 1. The difference of dose $(\Delta \mathrm{D})$ between confirmation $\mathrm{CT}$ and planning $\mathrm{CT}$ for each dose parameter $\left(D_{0.1 c c}, D_{1 c c}, D_{2 c c}\right)$ for organs at risk

\begin{tabular}{|c|c|c|c|c|c|c|c|c|c|}
\hline Patient & $\begin{array}{c}\Delta \mathrm{D}_{0.1 c c} \\
\text { sigmoid } \\
(\mathrm{cGy})\end{array}$ & $\begin{array}{c}\Delta \mathrm{D}_{1 \mathrm{cc}} \\
\text { sigmoid } \\
(\mathrm{cGy})\end{array}$ & $\begin{array}{c}\Delta \mathrm{D}_{2 \mathrm{cc}} \\
\text { sigmoid } \\
(\mathrm{cGy})\end{array}$ & $\begin{array}{c}\Delta \mathrm{D}_{0.1 \mathrm{cc}} \\
\text { rectum } \\
(\mathrm{cGy})\end{array}$ & $\begin{array}{c}\Delta \mathrm{D}_{1 \mathrm{cc}} \\
\text { rectum } \\
(\mathrm{cGy})\end{array}$ & $\begin{array}{c}\Delta \mathrm{D}_{2 \mathrm{cc}} \\
\text { rectum } \\
(\mathrm{cGy})\end{array}$ & $\begin{array}{c}\Delta \mathrm{D}_{0.1 c c} \\
\text { bladder } \\
(\mathrm{cGy})\end{array}$ & $\begin{array}{c}\Delta \mathrm{D}_{1 \mathrm{cc}} \\
\text { bladder } \\
(\mathrm{cGy})\end{array}$ & $\begin{array}{c}\Delta \mathrm{D}_{2 \mathrm{cc}} \\
\text { bladder } \\
\text { (cGy) }\end{array}$ \\
\hline $1 a$ & 165.97 & 127.11 & 102.57 & -73.27 & -83.58 & -74.46 & 19.16 & 38.59 & 33.83 \\
\hline $1 b$ & -149.19 & -98.61 & -89.37 & 54.28 & 14.23 & 12.62 & -37.79 & -29.75 & -25.87 \\
\hline $2 a$ & -71.12 & -61.38 & -56.5 & 3.6 & 31.99 & 36.27 & -88.04 & -29.04 & -11.41 \\
\hline $2 b$ & -74.13 & -64.75 & -73.57 & 84.81 & 62.25 & 57.73 & 275.8 & 616.38 & 518.09 \\
\hline $3 a$ & -57.05 & 9.77 & 31.83 & 150.05 & 92.91 & 70.73 & -169.13 & 16.1 & 41.75 \\
\hline $3 b$ & 116.85 & 132.58 & 142.8 & -312.58 & -280.04 & -255.26 & 144.76 & 126.29 & 111.35 \\
\hline $4 a$ & 181.24 & 81.89 & 59.7 & -64.49 & -62.01 & -55.65 & 361.37 & 198.37 & 144.82 \\
\hline $4 b$ & 89.74 & 80.04 & 88.85 & 5.51 & -2.4 & -9.58 & -474.66 & -230.23 & -153.19 \\
\hline $5 a$ & 67.39 & 46.07 & 37.71 & -44.42 & -25.23 & -17.13 & -32.05 & -68.75 & -74.18 \\
\hline $5 b$ & -31.97 & -37.23 & -33.55 & -68.89 & -43.17 & -31.32 & 382.05 & 144.32 & 85.38 \\
\hline $6 a$ & 15.69 & -59.55 & -71.37 & -15.57 & -4.67 & -5.65 & 19.72 & 15.53 & 25.2 \\
\hline $6 b$ & 66.22 & 10.82 & 7.45 & 16.8 & 16.59 & 21.54 & 217.21 & 111.44 & 80.88 \\
\hline $7 a$ & 138.85 & 101.78 & -8.93 & -15.51 & -9.52 & 47.55 & 33.4 & 34.87 & 47.55 \\
\hline $7 b$ & -81.74 & -1.45 & -8.69 & -338.83 & -327.05 & -305.16 & 139.46 & 119.07 & 111.38 \\
\hline $8 a$ & -33.34 & -128.95 & -134.32 & 137.69 & 76.65 & 61.61 & 111.61 & 90.65 & 78.69 \\
\hline $8 b$ & -287.86 & 65.35 & 29.4 & 38.55 & 35.71 & -8.63 & -12.51 & -15.83 & -8.63 \\
\hline $9 a$ & 376.44 & 212.42 & 158.52 & -8.86 & 2.14 & -1.72 & 702.03 & 288.59 & 193.85 \\
\hline $9 b$ & 30.54 & 10.52 & -10.87 & -5.38 & -4.67 & -4.01 & 60 & 71.75 & 32.76 \\
\hline $10 a$ & 88.76 & 94.5 & 70.43 & -113.8 & -98.76 & -66.7 & -5.89 & 46.67 & 21.63 \\
\hline $10 b$ & 25.72 & 12.81 & 12.63 & 110.65 & 105.6 & 75.7 & 125.86 & 155.83 & 115.87 \\
\hline Median & 25.72 & 11.82 & 10.0 & -7.12 & -3.53 & -4.83 & 46.7 & 59.21 & 44.65 \\
\hline
\end{tabular}

The median volume of sigmoid in the planning CT scan was $33.7 \mathrm{~cm}^{3}$ and $32.1 \mathrm{~cm}^{3}$ in the confirmatory CT. The median absolute volume change was $8.4 \mathrm{~cm}^{3}$ (range, $0.2-74.1 \mathrm{~cm}^{3}$ ), corresponding to $26 \%$ (range, $0.8-428.7 \%$ ). The dose for sigmoid for $\mathrm{D}_{0.1 \mathrm{cc}}$ was increased per each separate fraction by $25.7 \mathrm{cGy}$ for $\mathrm{D}_{0.1 \mathrm{cc}}, 11.8 \mathrm{cGy}$ for $\mathrm{D}_{1 \mathrm{cc} \prime}$ and $10.0 \mathrm{cGy}$ for $\mathrm{D}_{2 \mathrm{cc}}$ (Table 1, Figure 3A-C).

The relation between the planning time and the delta dose was evaluated. No significant changes were noted for sigmoid ( $R$ for $D_{0.1 \mathrm{cc}}$ was -0.2267 , for $\mathrm{D}_{1 \mathrm{cc}}-0.3482$, and for $\left.D_{2 c c}-0.3184\right)$ and bladder $\left(R\right.$ for $D_{0.1 c c}$ was 0.2067 , for $\mathrm{D}_{1 \mathrm{cc}}$ was 0.2637 , and for $\mathrm{D}_{2 \mathrm{cc}}$ was 0.2398 ). However, a statistically significant association between the planning time and delta dose was detected in all observed volumes for the rectum. The longer the planning, the higher the dose. The correlation coefficient for $\mathrm{D}_{01 \mathrm{cc}}$ was 0.6715 $(p=0.0061)$, for $\mathrm{D}_{1 c c}$ was $0.6404(p=0.011)$, and for $\mathrm{D}_{2 c c}$ was 0.5891 ( $p=0.0197)$.

The median absolute volume change for bladder, rectum, and sigmoid in plans created less vs. more than 54 minutes were $24.24 \mathrm{~cm}^{3}$ vs. $32.26 \mathrm{~cm}^{3}, 6.25 \mathrm{~cm}^{3}$ vs. $4.62 \mathrm{~cm}^{3}$, and $8.44 \mathrm{~cm}^{3}$ vs. $7.9 \mathrm{~cm}^{3}$, respectively. The medi- an delta dose between the original plans and actual plans for patients with a planning time more than 54 minutes and for women with shorter period of planning time than median was increased for rectum and bladder by 99 cGy and $91.9 \mathrm{cGy}$ for $\mathrm{D}_{0.1 \mathrm{cc}}, 61 \mathrm{cGy}$ and $52.1 \mathrm{cGy}$ for $\mathrm{D}_{1 \mathrm{cc}}$ and 29.8 cGy and 44.9 cGy for $D_{2 c c}$ per each fraction. On the contrary, a decrease of dose for sigmoid by 133.96 cGy, $70.3 \mathrm{cGy}$, and $48.6 \mathrm{cGy}$, respectively, was observed.

\section{Discussion}

Image-guided CT/MR brachytherapy significantly improves therapeutic results for patients with locally advanced cervical cancer $[11,16]$. The Gynecological GEC-ESTRO working group has initiated the multicenter observational EMBRACE studies ("Image-guided intensity modulated external beam chemoradiotherapy" and "MRI-based adaptive brachytherapy in locally advanced cervical cancer"), bringing new data regarding locoregional control, nodal control, overall survival, morbidity, quality of life, and prognostic and predictive parameters $[17,18,19,20]$. 
A

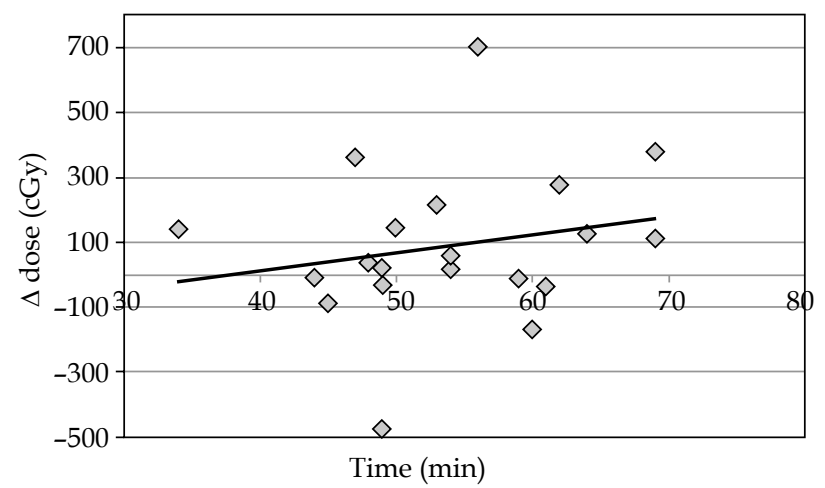

C

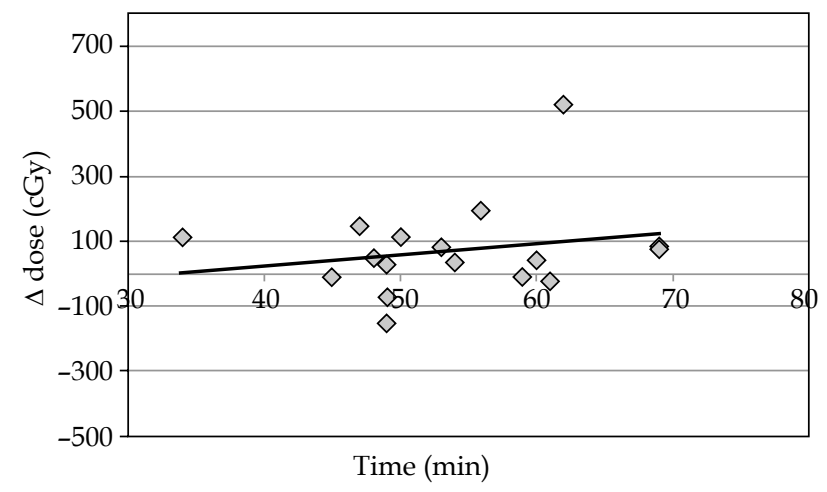

A

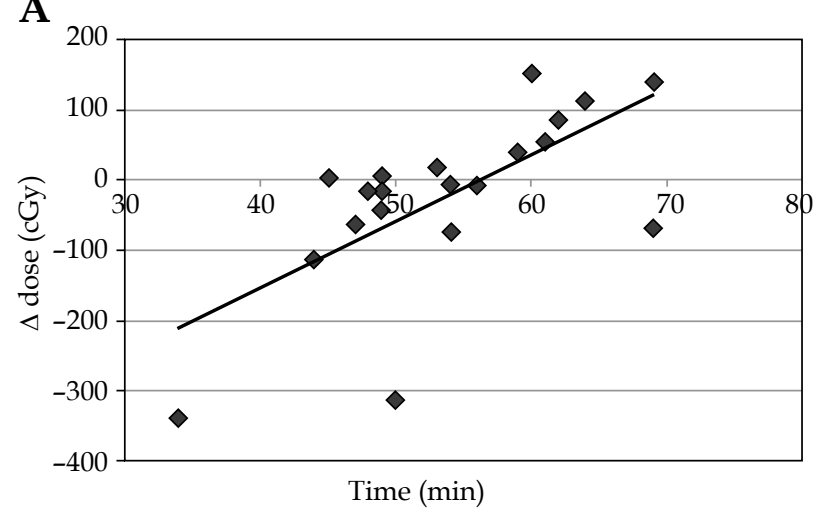

C

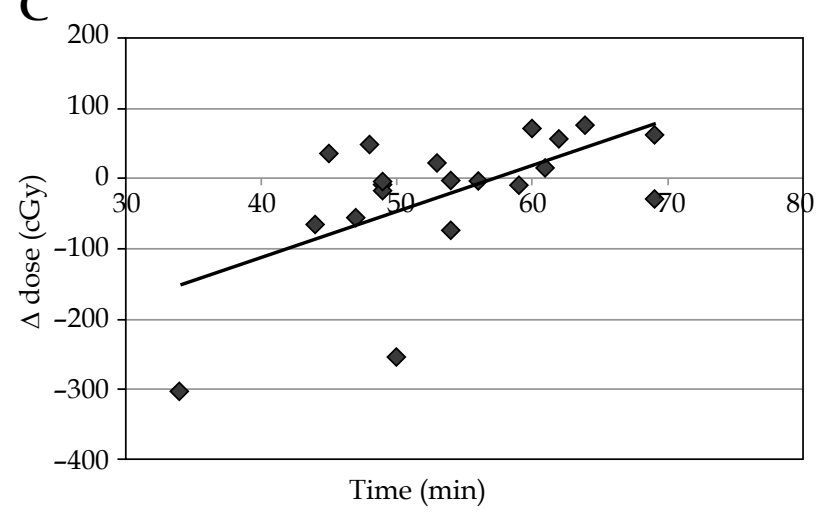

B

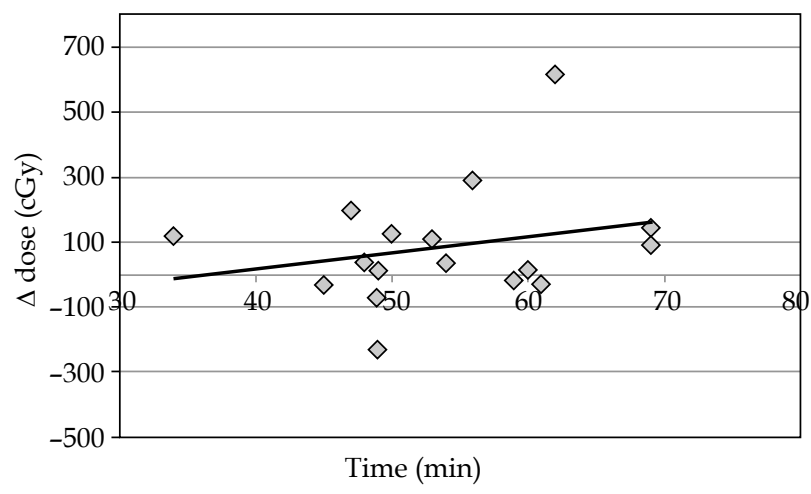

Fig. 1. A) Time vs. change of dose for $D_{0.1 c c}$ bladder; B) Time vs. change of dose for $D_{1 c c}$ bladder; C) Time vs. change of dose for $\mathrm{D}_{2 \mathrm{cc}}$ bladder

B

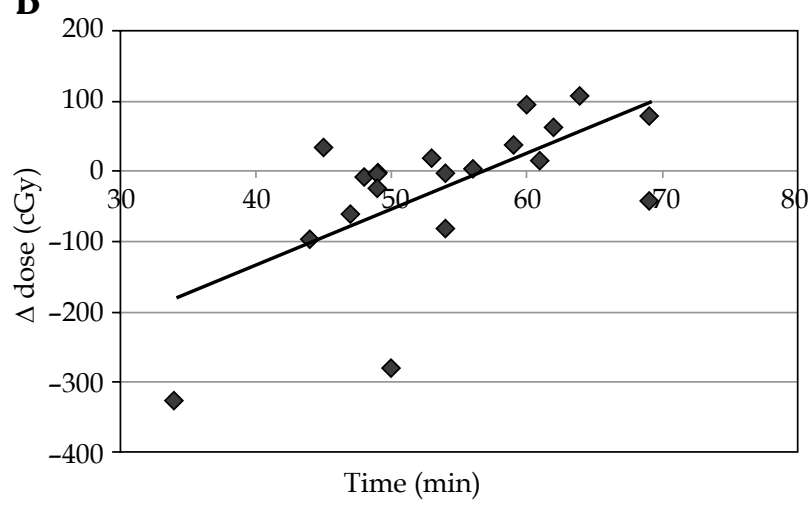

Fig. 2. A) Time vs. change of dose for $D_{0.1 c c}$ rectum; B) Time vs. change of dose for $D_{1 \mathrm{cc}}$ rectum; C) Time vs. change of dose for $\mathrm{D}_{2 \mathrm{cc}}$ rectum 
A

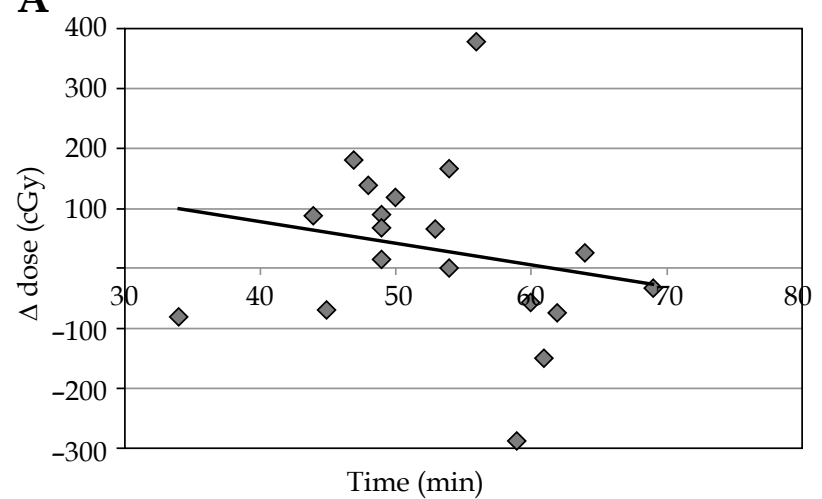

C

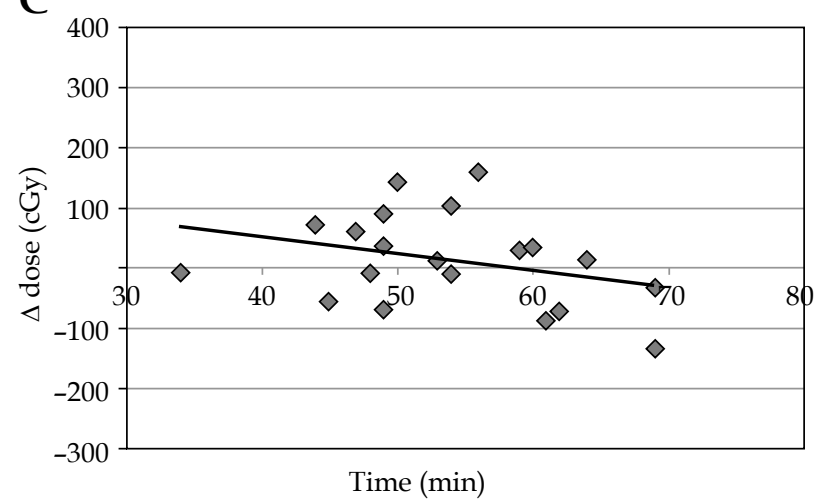

The 3D treatment planning time is more time-consuming than regular 2D planning. Based on the changes of small pelvis topography in time, the focus of the present study was to determine whether a longer treatment planning time can have dosimetric consequences with regards to the dose for organs at risk [21,22]. The most significant changes observed were for the rectum. With the prolongation of planning time, the rectal volume increased, leading to a significant dose increase. The median delta doses between the original plans and actual plans were compared for women with planning time longer than median (54 minutes) and patients with shorter planning time. A dose increase of $99 \mathrm{cGy}$ for $\mathrm{D}_{0.1 \mathrm{cc}} 61 \mathrm{cGy}$ for $\mathrm{D}_{1 \mathrm{cc}}$ and $29.8 \mathrm{cGy}$ for $\mathrm{D}_{2 \mathrm{cc}}$ per each fraction was observed in women with planning time longer than 54 minutes. In comparison with the median original planning dose, this means a possible increase by $22.3 \%$ for $D_{0.1 c c}$ $18.4 \%$ for $\mathrm{D}_{1 \mathrm{cc} \mathrm{c}^{\prime}}$ and $9.6 \%$ for $\mathrm{D}_{2 \mathrm{cc}}$. We believe that most important reasons for the difference in planning times was difficulties in some of the plans with respect to the small pelvis topography and due to time-consuming manual optimization used.

Interestingly, correlation between change of volume and change of the dose was confirmed only for rectum. It is possible that changes in volume in sigmoid and bladder are more variable, while increasing the volume of rectum during planning process is more associated with the reduction of distance between rectum wall and applicators.

To the best of our knowledge, this is the first study focusing on the impact of planning time on the actual dose to organ at risk. Based on the present results, it seems
B

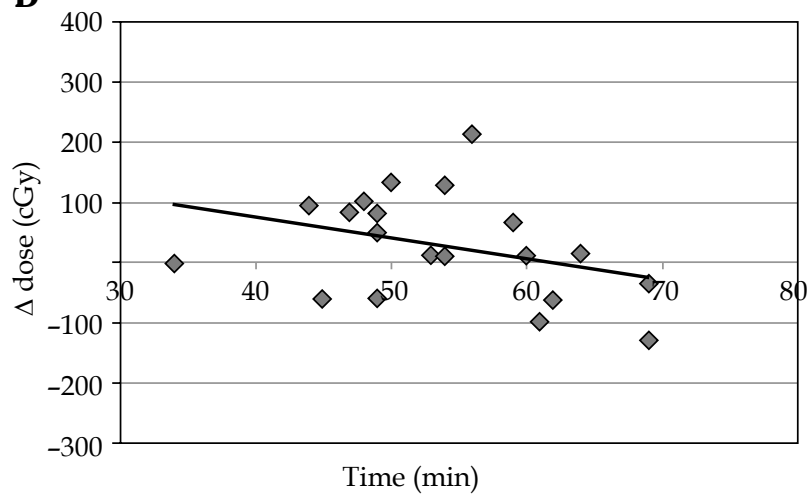

Fig. 3. A) Time vs. change of dose for $D_{0.1 c c}$ sigmoid; B) Time vs. change of dose for $\mathrm{D}_{1 \mathrm{cc}}$ sigmoid; $\left.\mathrm{C}\right)$ Time vs. change of dose for $\mathrm{D}_{2 \mathrm{cc}}$ sigmoid

that longer period of high-dose-rate (HDR) brachytherapy planning time can lead to incorrect estimation of dose distribution, principally to the rectum. The actual dose distribution does not correspond to the dose distribution at planning $\mathrm{CT}$, because of the temporal changes in pelvic topography. It is therefore imperative to decrease the planning time.

The small number of patients is a significant limitation of the present study. In order to fully confirm current observations, a larger patient cohort is needed. However, despite this limitation, the present data support the conclusion that the planning time affects the real dose distribution. Based on these findings, a strive for a minimal delay between application and radiotherapy seems to be appropriate.

\section{Conclusions}

Extended brachytherapy planning time for brachytherapy due to changes in topography of small pelvis can lead to different dosage in high-risk organs than previously planned. It seems that the most significant changes are related to the rectum.

\section{Disclosure}

The authors report no conflict of interest.

\section{References}

1. Han K, Milosevic M, Fyles A et al. Trends in the utilization of brachytherapy in cervical cancer in the United States. Int J Radiat Oncol Biol Phys 2013; 87: 111-119. 
2. Fellner C, Pötter R, Knocke T et al. Comparison of radiography-and computed tomography-based treatment planning in cervix cancer in brachytherapy with specificn attention to some quality assurance aspects. Radiother Oncol 2001; 58: 53-62.

3. Pötter R, Dimopoulos J, Georg P et al. Clinical impact of MRI assisted dose volume adaptation and dose escalation in brachytherapy of locally advanced cervix cancer. Radiother Oncol 2007; 83: 148-155.

4. Dolezel M, Odrazka K, Vanasek J et al. MRI-based preplanning in patients with cervical cancer treated with $3 \mathrm{D}$ brachytherapy. Br J Radiol 2011; 84: 850-856.

5. Dolezel M, Odrazka K, Zizka J et al. MRI-based preplanning using CT and MRI data fusion in patients with cervical cancer treated with 3D-based brachytherapy: feasibility and accuracy study. Int J Radiat Oncol Biol Phys 2012; 84: 146-152.

6. Gerbaulet A, Potter R, Mazeron JJ et al. (eds.). The GEC ESTRO Handbook of Brachytherapy 2003.

7. Shin K, Kim T, Cho J et al. CT-guded intracavitary radiotherapy for cervical cancer: Comparison of conventional Point A plan with clinical target volume-based 3D plan using dose-volume parameters. Int J Radiat Oncol Biol Phys 2006; 64: 197-204.

8. van Heerden LE, Visser J, Koedooder K et al. Role of deformable image registration for delivered dose accumulation of adaptive external beam radiation therapy and brachytherapy in cervical cancer. J Contemp Brachytherapy 2018; 10: 542-550.

9. Murakami N, Shima S, Kashihara $\mathrm{T}$ et al. Hyaluronic gel injection into the vesicovaginal septum for high-dose-rate brachytherapy of uterine cervical cancer: an effective approach for bladder dose reduction. I Contemp Brachytherapy 2019; 11: 1-7.

10. Mahantshetty U, Gudi S, Singh R et al. Indian Brachytherapy Society Guidelines for radiotherapeutic management of cervical cancer with special emphasis on high-dose-rate brachytherapy. J Contemp Brachytherapy 2019; 11: 293-306.

11. Pötter R, Georg P, Dimopoulos JC et al. Clinical outcome of protocol based image (MRI) guided adaptive brachytherapy combined with 3D conformal radiotherapy with or without chemotherapy in patients with locally advanced cervical cancer. Radiother Oncol 2011; 100: 116-123.

12. Haie-Meder C, Potter R, Van Limbergen E et al. Recommendations from Gynaecological (GYN) GEC-ESTRO Working Group(I): Concepts and terms in 3D image based 3D treatment planning in cervix cancer brachytherapy with emphasis on MRI assessment of GTV and CTV. Radiother Oncol 2005 74: 235-245.

13. Pötter R, Haie-Meder C, Van Limbergen E et al. Recommendations from gynaecological (GYN) GEC ESTRO working group(II): concepts and terms in 3D image-based treatment planning in cervix cancer brachytherapy-3D dose volume parameters and aspects of 3D image-based anatomy, radiationphysics, radiobiology. Radiother Oncol 2006; 78: 67-77.

14. Hellebust TP, Kirisits C, Berger D et al. Recommendations from Gynaecological (GYN) GEC-ESTRO Working Group: considerations and pitfalls in commissioning and applicator reconstruction in 3D image-based treatment planning of cervix cancer brachytherapy. Radiother Oncol 2010; 96: 153-160.

15. Dimopoulos JC, Petrow P, Tanderup K et al. Recommendations from Gynaecological (GYN) GEC-ESTRO Working Group (IV): Basic principles and parameters for MR imaging within the frame of image based adaptive cervix cancer brachytherapy. Radiother Oncol 2012; 103: 113-122.

16. Lindegaard JC, Fokdal LU, Nielsen SK et al. MRI-guided adaptive radiotherapy in locally advanced cervical cancer from a Nordic perspective. Acta Oncol 2013; 52: 1510-1519.

17. Sturdza A, Pötter R, Fokdal LU et al. Image guided brachytherapy in locally advanced cervical cancer: Improved pelvic control and survival in RetroEMBRACE, a multicenter cohort study. Radiother Oncol 2016; 120: 428-433.

18. Tanderup K, Fokdal LU, Sturdza A et al. Effect of tumor dose, volume and overall treatment time on local control after radiochemotherapy including MRI guided brachytherapy of locally advanced cervical cancer. Radiother Oncol 2016; 120: 441-446.

19. Kirchheiner K, Pötter R, Tanderup K et al. Health-related quality of life in locally advanced cervical cancer patients after definitive chemoradiation therapy including image guided adaptive brachytherapy: an analysis from the EMBRACE study. Int J Radiat Oncol Biol Phys 2016; 94: 1088-1098.

20. Mazeron R, Fokdal LU, Kirchheiner K et al. Dose-volume effect relationships for late rectal morbidity in patients treated with chemoradiation and MRI-guided adaptive brachytherapy for locally advanced cervical cancer: Results from the prospective multicenter EMBRACE study. Radiother Oncol 2016; 120: 412-419.

21. Siavashpour Z, Aghamiri MR, Jaberi R et al. Optimum organ volume ranges for organs at risk dose in cervical cancer intracavitary brachytherapy. J Contemp Brachytherapy 2016; 8: 135-142.

22. Schindel J, Zhang W, Bhatia SK et al. Dosimetric impacts of applicator displacements and applicator reconstruction-uncertainties on 3D image-guided brachytherapy for cervical cancer. J Contemp Brachytherapy 2013; 5: 250-257. 